\title{
Diversity of Lithic Assemblages and Evolution of Late Palaeolithic Culture in Korea
}

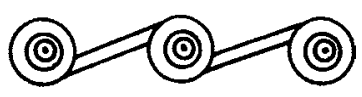

\author{
CHUNTAEK SEONG
}

\section{INTRODUCTION}

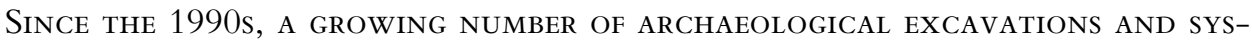
TEMATIC SURVEYs in Korea have provided a rapid accumulation of Palaeolithic archaeological data: more than 1000 locations with archaeological remains are recognized and mapped, while some 200 sites were archaeologically excavated in the southern Korean Peninsula (Fig. 1, Table 1). This growth of Palaeolithic research has enabled archaeologists to discuss various issues including chronology, lithic technology, and site function and structure.

One of the key characteristics of the Late Palaeolithic in Korea is the diversity of lithic assemblages. While the Late or Upper Palaeolithic in general is characterized by blades and blade industries, tanged points are important components of Early Late Palaeolithic lithic assemblages, which often do not contain blades. Lithic assemblages made of coarse quartzite and vein quartz persisted even until the end of the Pleistocene, while blades and microblades dominate other lithic assemblages. In what follows, I review the complexity of lithic assemblages and attempt to derive a picture of the evolution of lithic technology in the Late Palaeolithic.

\section{THE LATE PALAEOLITHIC CONCEPT}

Discussions of Korean and East Asian Palaeolithic sequences have been impeded by the continual use of the conventional time frame for the European Lower-MiddleUpper Palaeolithic (Gao and Norton 2002; Ikawa-Smith 1978; Seong 2002). Despite wide differences in dates in different regions in the Old World, the subdivision of the Palaeolithic known as the Middle Palaeolithic (in Europe and Asia) or Middle Stone Age (in Africa) is widely used to denote a time period lasting from 300,000-200,000 to 40,000-30,000 years ago. In Korea, however, assemblages that seem older than 40,000 B.P. are conventionally referred to as the Lower or Middle Palaeolithic, often without specific definition (see K. Bae 2013 for a recent review of this problem). The span of the Middle Palaeolithic in Korea is arbitrarily framed to range between 100,000 or 80,000 and 40,000-35,000 years ago (Park 2002; Yi 1989), even though there is 


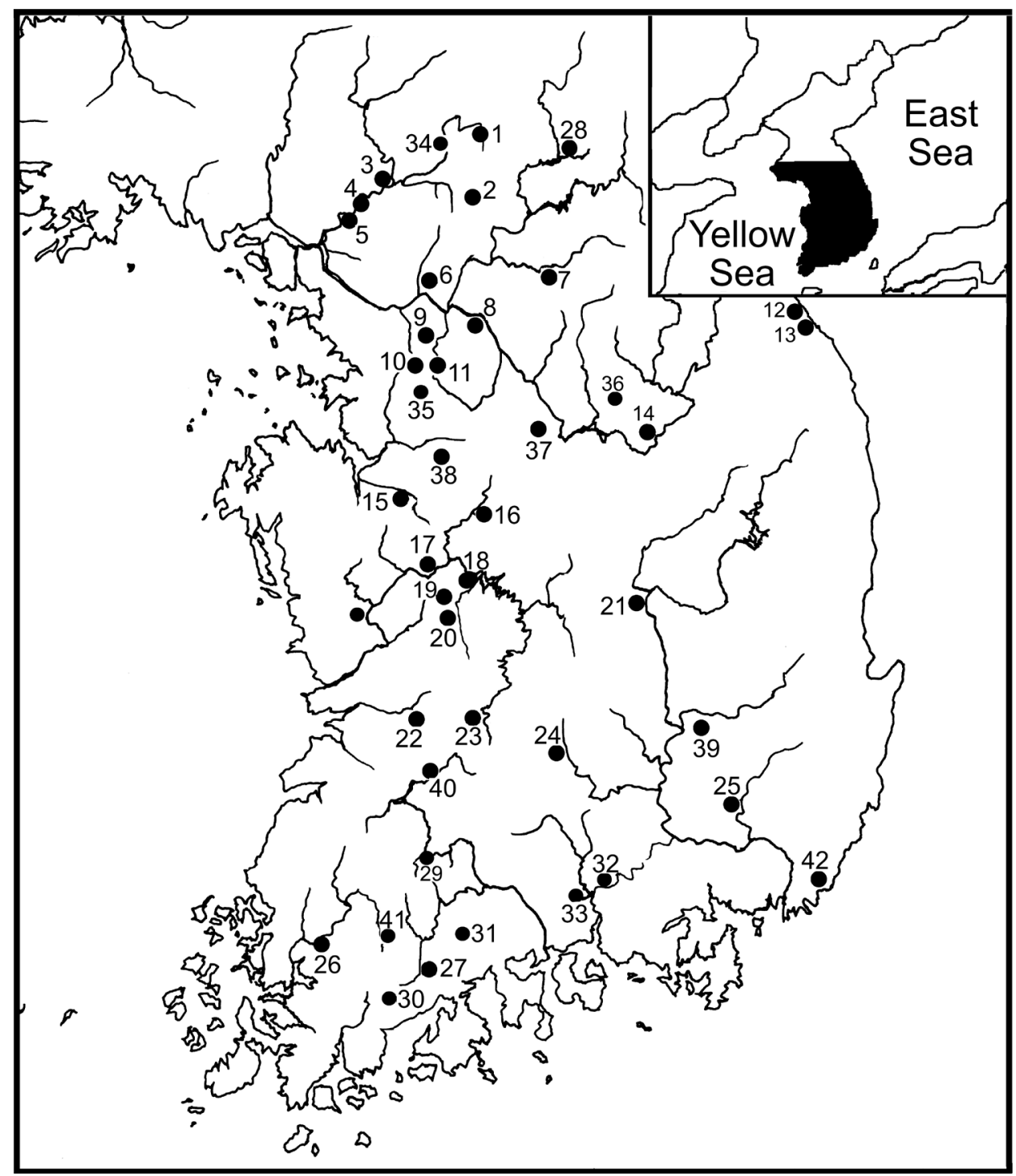

Fig. 1. Distribution of Late Palaeolithic sites in the southern Korean Peninsula (revised based on Seong 2009:429, Figure 1). 1: Jangheung-ri, 2: Hwadae-ri, 3: Jeongok-ri, 4: Juwol/Gawol-ri, 5: Geumpa-ri, 6: Hopyeong-dong, 7: Hahwagye-ri, 8: Byeongsan-ri, 9: Sam-ri, 10: Dongbaek-ri, 11: Pyeongchang-ri, 12: Dobong, 13: Gigok, 14: Suyanggae, 15: Silok-dong, 16: Bongmyeong-dong, 17: Seokjang-ri, 18: Yongho-dong/Nosan-ri, 19: Yongsan-dong, 20: Daejeong-dong, 21: Sinsang-ri, 22: Songcheondong/Bonggok, 23: Jingeuneul, 24: Jeongjang-ri, 25: Gorye-ri, 26: Dangga, 27: Wolpyeong, 28: Sangmyryong-ri, 29: Okgwa (Songjeon-ri/Jusan-ri), 30: Sinbuk, 31: Juknae-ri, 32: Jiphyeon, 33 : Naechon-ri, 34: Jung-ri, 35: Cheon-ri, 36: Jungmal, 37: Songam-ri, 38: Suheol-ri, 39: Wolseong-dong, 40: Haga, 41: Sachang, 42: Jung-dong/Jwa-dong. 
no convincing evidence for the characteristic technological and behavioral features for the time period (Seong 2002).

In general in Europe and Africa, Middle Palaeolithic or Mousterian technology is characterized by cores prepared using the Levallois technique (whether called that or not). This technique provided greater control over the shape and size of flakes detached from prepared cores than earlier (Lower Palaeolithic) techniques. In Europe, Middle Palaeolithic assemblages were made and used by Neanderthals; thus, the Middle Palaeolithic is understood as the culture of the Neanderthals.

The Middle Palaeolithic concept (and dividing the Palaeolithic into three periods) is inappropriate in East Asian contexts (Gao and Norton 2002; Seong 2002). While we need more research to outline the sequential change of lithic technology during the Palaeolithic, we do not have enough evidence to typify the period traditionally known as the Middle Palaeolithic in East Asia. While Middle Palaeolithic and Levallois concepts are applied in Siberian contexts (Derev'anko and Markin 1998; Derevianko et al. 2004), the concept is controversial in Korea and adjacent regions of Northeast Asia. No Palaeolithic phase in Korea can be characterized by having prepared core technology or use of the Levallois technique.

As I discuss elsewhere (Seong 2004), while an increasing number of flakes and tools made on flakes appear toward the Upper or Late Palaeolithic, it is difficult to characterize a Middle period as opposed to the Lower or Early Palaeolithic. That is why two subdivisions, Early and Late, are more appropriate in East Asian and Korean contexts. Early Palaeolithic assemblages are dominated by quartzite and vein quartz artifacts including large cores, flakes, polyhedrals, choppers, and hand axes, along with small flakes and scrapers. While the number of small artifacts and flakes made of locally available quartzite and vein quartz increases toward the time typically known as the Middle-Upper Palaeolithic transition, no significant traits such as specific prepared core techniques delineate a specific time period comparable to the Western Eurasian Middle Palaeolithic. The Korean Late Palaeolithic, however, largely parallels the Western Eurasian Upper Palaeolithic, including a prevalence of blade and microlithic industries using fine-grained rocks.

\section{LATE PALAEOLITHIC CHRONOLOGY AND ASSEMBLAGE TYPES}

\section{Dating the Lithic Assemblages}

A growing accumulation of chronometric dates allows researchers to establish at least a sketchy chronological sequence. More than one hundred radiocarbon dates have been recovered (Table 1). The OSL (Optically Stimulated Luminescence) dating technique is regularly applied to Palaeolithic deposits, providing at least one means of evaluating the absolute dates derived from AMS (Accelerator Mass Spectrometry) dating (Graf 2009; Seong 2011). While it is very difficult to accept chronometric dates at face value, the growing number of cross-checked dates has allowed researchers to evaluate their reliability and make archaeological interpretations.

As I presented elsewhere (Seong 2011), radiocarbon dates can be evaluated based on dated materials (i.e., dispersed charcoals vs. soil samples, along with their associated contexts with lithic assemblages), margins of error, and correlation of multiple dates. We need to be cautious regarding the dates of soil samples, but can critically evaluate OSL dates based on their correspondence with radiocarbon dates. 


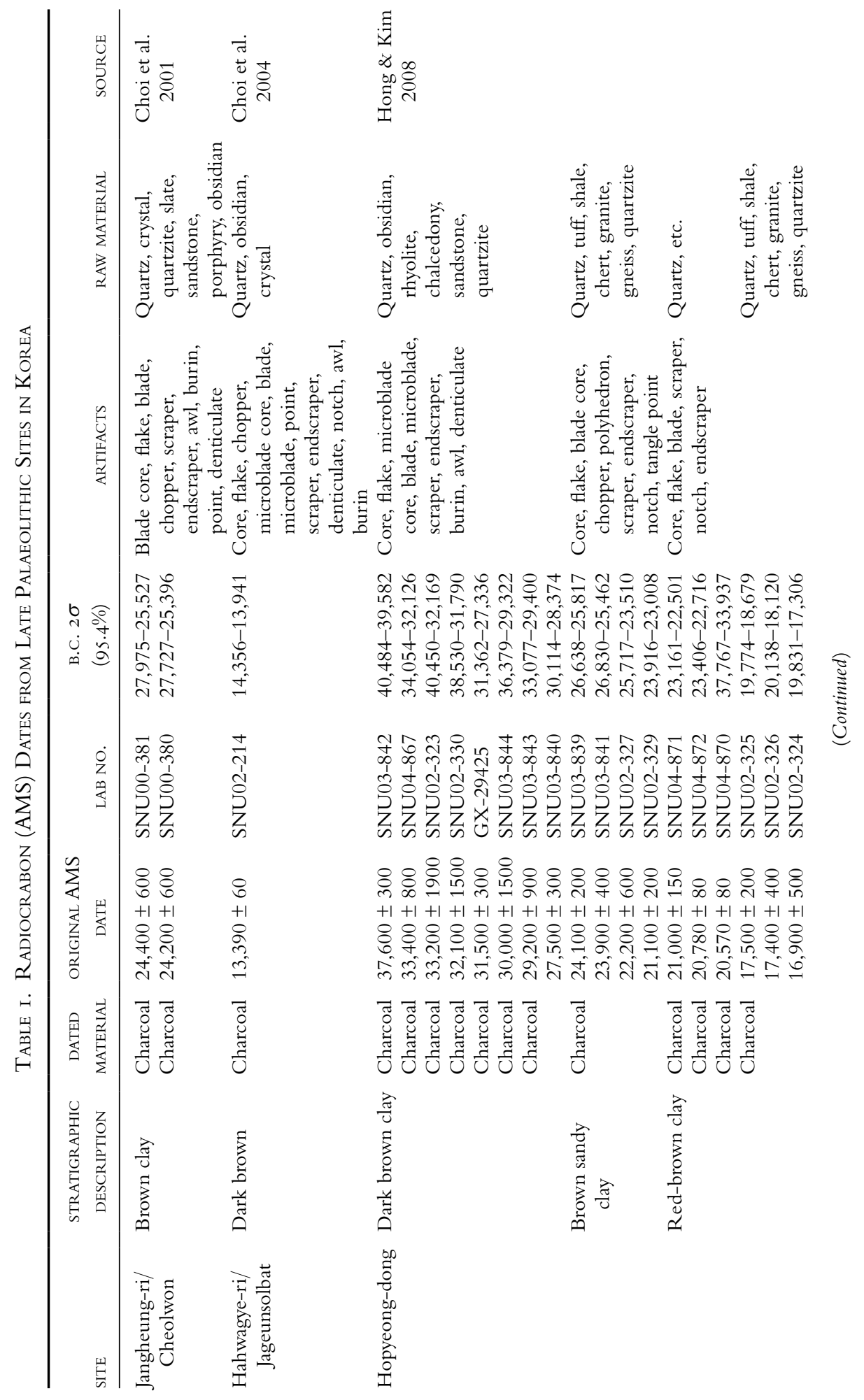




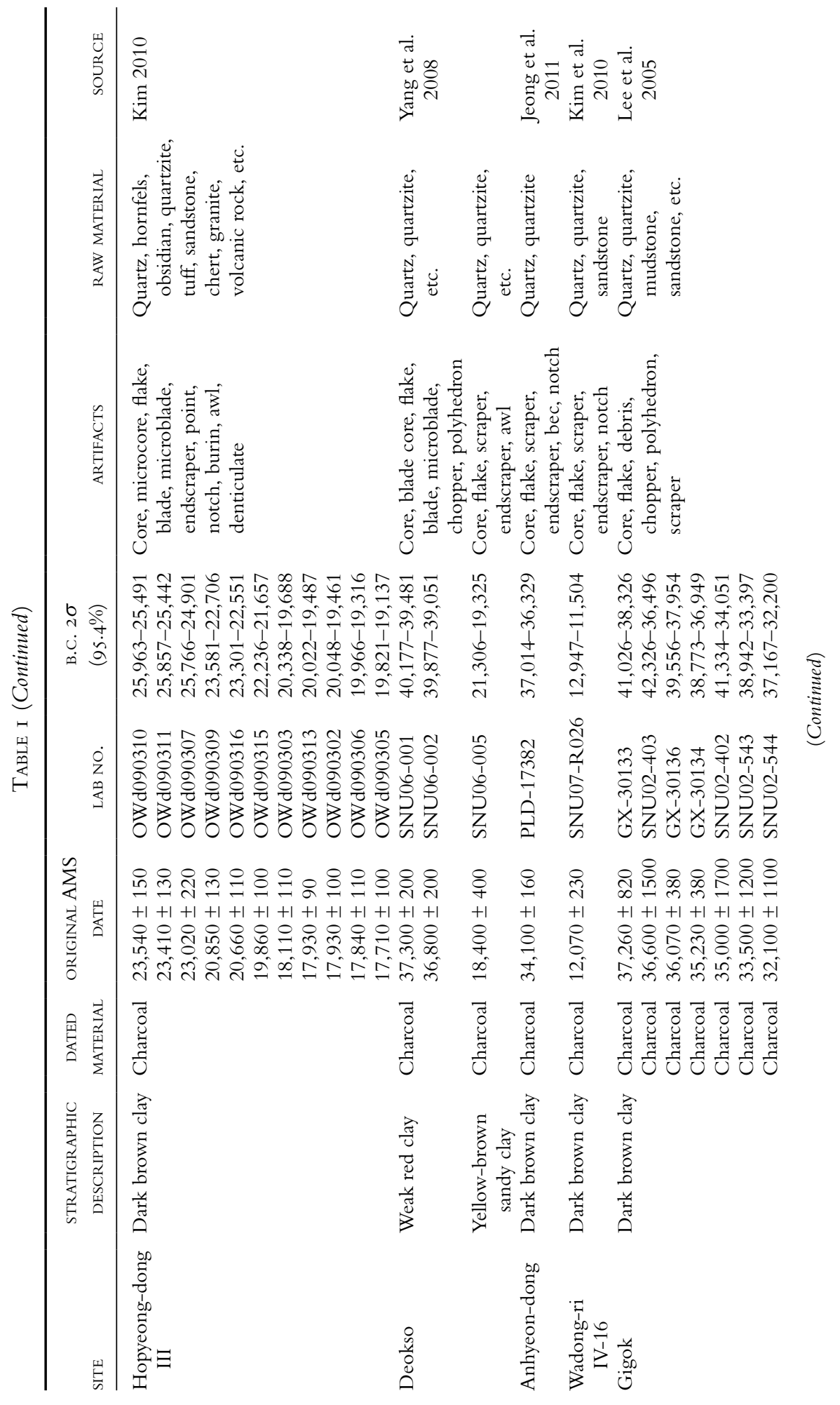




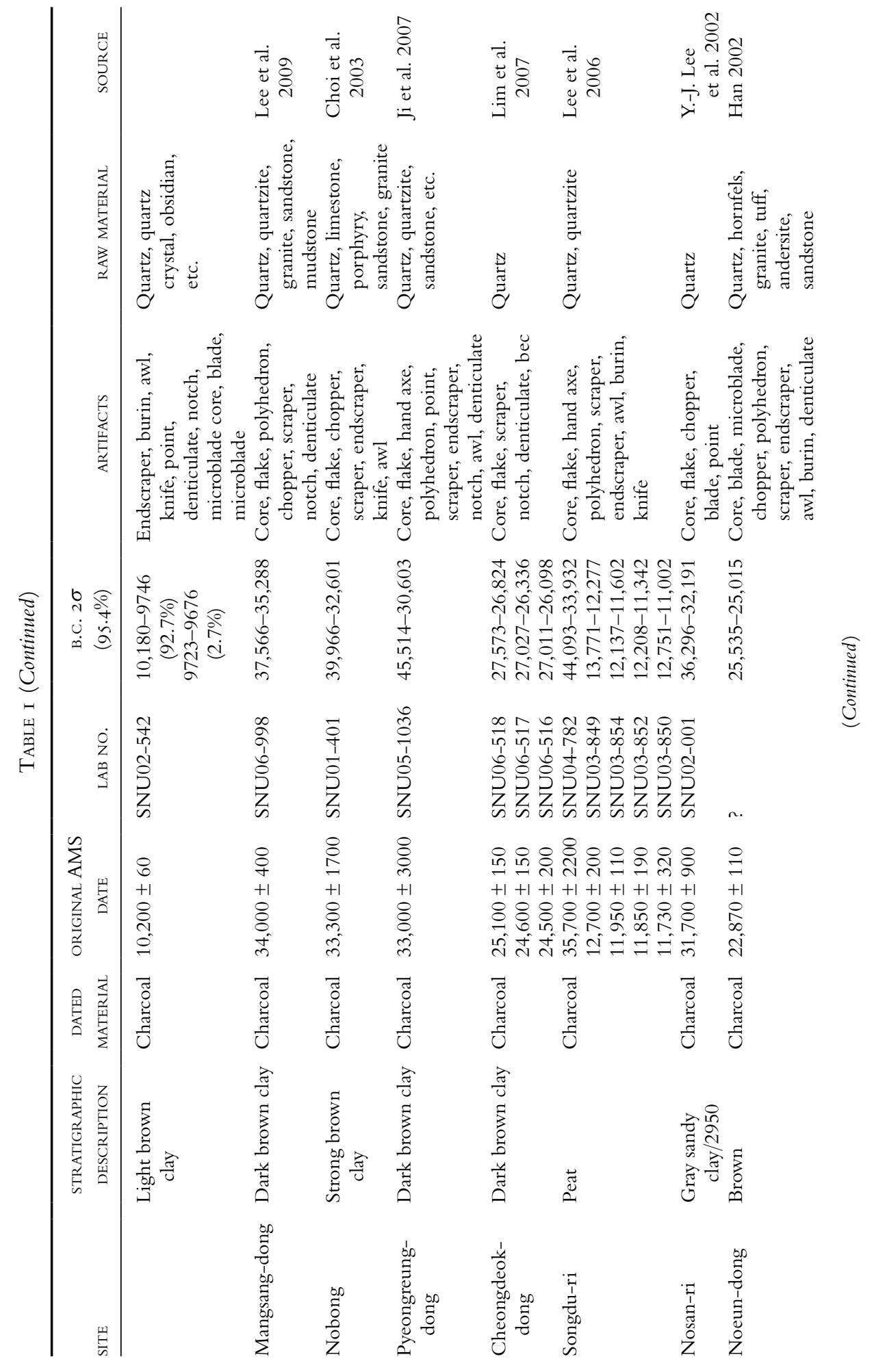




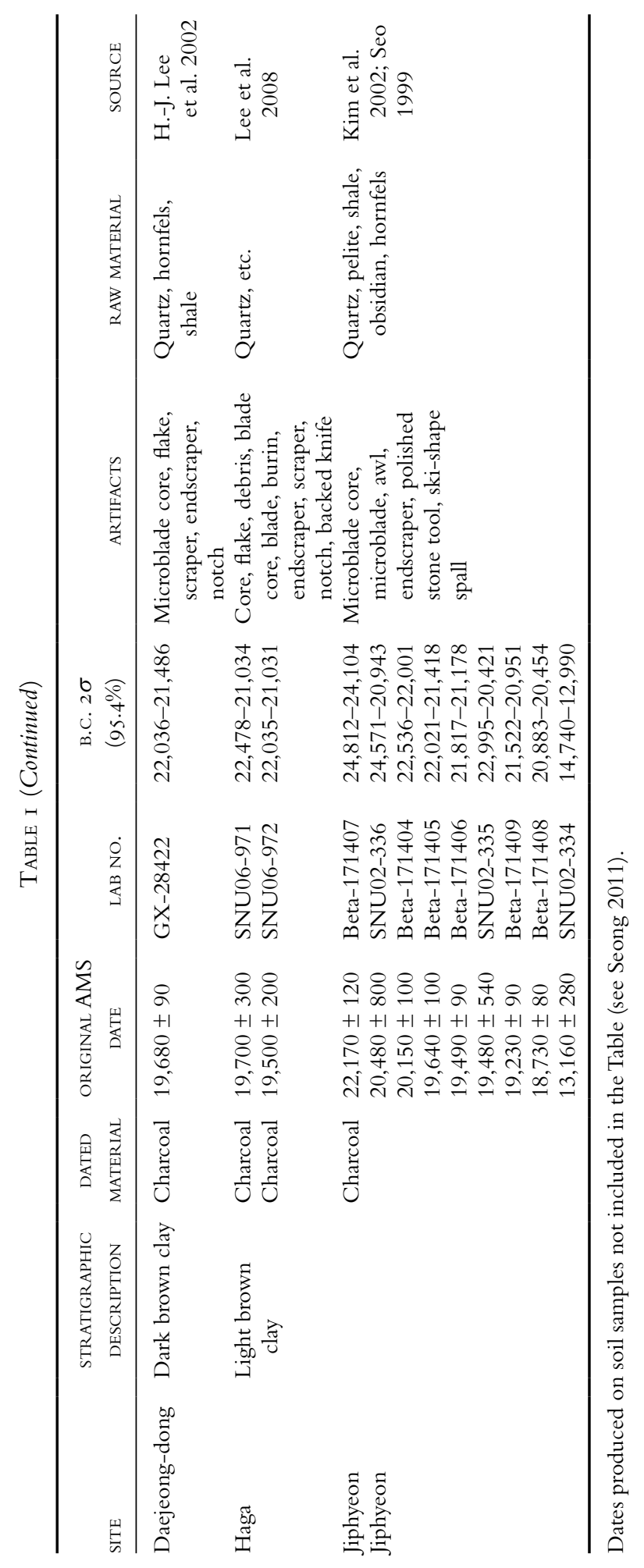


In the late 1990s, the discovery of AT (Aira Tanzawa) tephra, flown in from southern Kyushu where they had been securely dated to 28,000-25,000 years ago, provided another means of building a chronology (Yi et al. 1998). This tephrachronology is widely accepted throughout the southern Korean Peninsula; it has provided a valuable way to test other chronometric dates.

Tables 1 and 2 summarize radiocarbon dates from Late Palaeolithic sites in Korea; these dates have been evaluated according to the cross-checking processes outlined above.

\section{Some Stratified Sites}

An overview of finds from stratified sites such as Hopyeong-dong and Gigok provide another glimpse of the Late Palaeolithic sequence in Korea.

At Gigok (Locality B) in the east coast, quartzite flakes, polyhedrals, and scrapers were uncovered from a layer that was AMS dated to 33,500 \pm 1200 B.P. $(38,120 \pm 2772$ cal B.P.) and 32,100 \pm 1100 в.P. (36,634 \pm 2483 cal в.P.). The upper horizon of light brown clayey silt yielded 5172 artifacts made of quartzite, quartz crystal, siliceous shale, and obsidian; the artifiacts included scrapers, endscrapers, blades, microblades, and microcores. This upper horizon was dated to 10,200 \pm 60 B.P., or 11,913 \pm 217 cal B.P., one of the youngest dates for Palaeolithic assemblages in Korea (Lee et al. 2005).

Table 2. Four Assemblage Types or Complexes for the Korean late Palaeolithic as Recognized by Characteristic Artifact Types

\begin{tabular}{|c|c|}
\hline $\begin{array}{l}\text { ASSEMBLAGE WITH } \\
\text { CHARACTERISTIC ARTIFACTS }\end{array}$ & SELECTED SITES AND DATES* \\
\hline $\begin{array}{l}\text { Quartzite and vein quartz } \\
\text { artifacts }\end{array}$ & $\begin{array}{l}\text { Gigok (lower, } 33,500 \pm 1200[38,120 \pm 2772 \text { cal B.P. }], 32,100 \pm 1100 \\
{[36,634 \pm 2483 \text { cal B.P.]), Dongbaek-ri }(27,000 \pm 300)} \\
\text { Pyeongchang-ri, Jeongok (upper), Yullyang-dong }(22,360 \pm 120 \\
\text { Songdu-ri }(11,730 \pm 320,11,850 \pm 190,11,950 \pm 110)\end{array}$ \\
\hline $\begin{array}{l}\text { Tanged points only } \\
\text { (Songam-ri Complex) }\end{array}$ & $\begin{array}{l}\text { Songam-ri }(33,300 \pm 160[37,576 \pm 695 \text { cal B.P. }], 33,190 \pm 160 \\
\quad[37,428 \pm 707 \text { cal B.P. }]), \text { Hwadae-ri }(31,200 \pm 900[35,741 \pm 2000 \\
\text { cal B.P. }]) \text {, Yongho-dong }(38,500 \pm 1000)\end{array}$ \\
\hline $\begin{array}{l}\text { Tanged points and blades } \\
\text { (Gorye-ri Complex) }\end{array}$ & $\begin{array}{l}\text { Yongsan-dong }(24,430 \pm 870[28,983 \pm 1706 \mathrm{cal} \text { B.P. }]) \text {, Hopyeong-dong } \\
(27,500 \pm 300[29,544 \pm 570 \mathrm{cal} \text { B.P. }], 27,600 \pm 300[31,628 \pm 633 \\
\text { cal B.P.], } 24,100 \pm 200,23,900 \pm 400) \text {, Gorye-ri (AT tephra) }\end{array}$ \\
\hline $\begin{array}{l}\text { Tanged points and } \\
\text { microliths } \\
\text { (Suyanggae Complex) }\end{array}$ & $\begin{array}{l}\text { Jangheung-ri }(24,400 \pm 600[28,701 \pm 1224 \text { cal B.P. }], 24,200 \pm 600 \\
[28,521 \pm 1156 \text { cal B.P. }]), \text { Suyanggae }(16,400 \pm 600,18,630 \\
\text { conventional), Hajin-ri, Seokjang-ri, Jingeuneul }(22,850 \pm 350 \\
17,310 \pm 80[20,884 \pm 259 \text { cal B.P. }]) \text {, Sinbuk }(25,420 \pm 190 \\
{[29,580 \pm 577 \text { cal B.P. }], 23,850 \pm 160[27,969 \pm 332 \text { cal B.P. }]} \\
20,960 \pm 80,21,760 \pm 190)\end{array}$ \\
\hline $\begin{array}{l}\text { Microlithics only } \\
\text { (Hahwagye-ri Complex) }\end{array}$ & 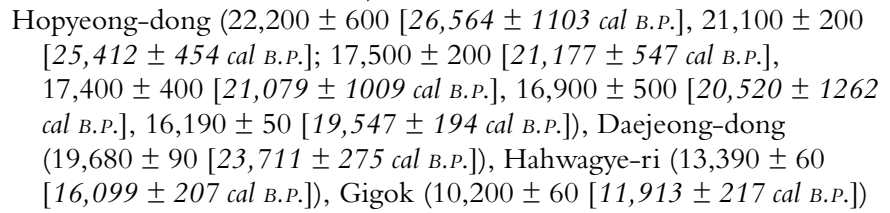 \\
\hline
\end{tabular}

* Calibrated dates using the OxCal program based on IntCal13 curve are italicized. 
At Hopyeong-dong (Section D), the lower horizon (Layer 3b) yielded a total of 3023 artifacts, including flakes, cores, scrapers, and endscrapers, made of vein quartz (95.7\% of the total assemblage), tuff, shale, and chert (Hong and Kim 2008) (Fig. 2). Among the assemblages, three tanged points made of silicified tuff (shale) are most notable. AMS dates of $27,600 \pm 300$ and $27,500 \pm 300$ B.P. for Section D suggest they could be as much as 30,000 years old (31,628 \pm 633 cal B.P. and 29,544 \pm 570 cal B.P., respectively). The upper horizon at Section A, where 864 obsidian artifacts were collected, is characterized by microblades, microdrills, and microcores. This horizon is dated to $21,100 \pm 200$ в.P. $(25,412 \pm 454$ cal в.P.) and $22,200 \pm 600$ в.P. $(26,564 \pm 1103$ cal B.P.). These dates mark the first known use of obsidian as lithic raw material in Korea. The last horizon at Section C, where 46 siliceous shale microblades were collected, has been dated to $16,190 \pm 50$ в.P. $(19,547 \pm 194$ cal в.P.), $16,900 \pm 500$ в.Р. $(20,520 \pm 1262$ cal в.P. $), 17,500 \pm 400$ в.P. $(21,177 \pm 547$ cal в.P. $)$, and $17,400 \pm 400$ в.P. $(21,079 \pm 1009$ cal в.P.) (Table 1).

\section{Assemblage Types}

The dates and artifact assemblages presented in Table 2 provide an overview of the diversity of lithic assemblage types or complexes within a chronological frame.

First, note that the lithic assemblages do not contain characteristic Late Palaeolithic artifacts such as blades, microblades, or tanged points. Despite a lack of direct radiocarbon dates from these locations, the discovery of AT tephra suggests that assemblages from the upper horizons at Jeongok-ri, Gawol-ri, and many Imjin-Hantan River Basin (IHRB) sites date to 30,000-20,000 years ago (Yi et al. 1998). AMS dates from Songdu-ri range from 11,730 $\pm 320,11,850 \pm 190,11,950 \pm 110$, and $12,700 \pm 200$, that is, from 14,500 to 13,500 B.P. once calibrated (H.-J. Lee 2004). This suggests that lithic assemblages characterized by quartzite and vein quartz artifacts lasted until the end of the Pleistocene.

Many sites in the southern Gyeonggi and Chungcheong regions can be grouped into this category of small quartzite and vein quartz assemblages. These assemblages were characterized by small quartzite and vein quartz artifacts, but included some large artifacts such as cores and choppers. Artifact types included scrapers, endscrapers, notches, denticulates, points, and backed knives; prepared and pseudo-prismatic cores were also included. Compared to earlier Palaeolithic assemblages, these lithic assemblages are dominated by small artifacts and diverse tool types. While there are no typical blades, the cores suggest that small, elongated flakes had been detached from them. Small artifacts such as trapezoids and backed knives were notable in these Late Palaeolithic quartzite and vein quartz assemblages. They tend to have been made from high-quality raw material (e.g., the Pyeongchang-ri collection) (Seong 2004; Yi et al. 2000).

Another assemblage type that can be derived from the data in Table 2 is the tanged-point dominated assemblage. While tanged points unearthed from Songam-ri, Hwadae-ri, and Yongho-dong are not associated with any blades, they are associated with blades and blade cores at Yongsan-dong, Gorye-ri, and the lower horizon of Hopyeong-dong; they are even associated with microblades and microcores at Suyanggae, Sinbuk, and Jangheung-ri. AMS dates from tanged-point-only assemblages suggest that tanged points emerged some 35,000-30,000 B.P. or 40,000-35,000 calibrated years ago. 

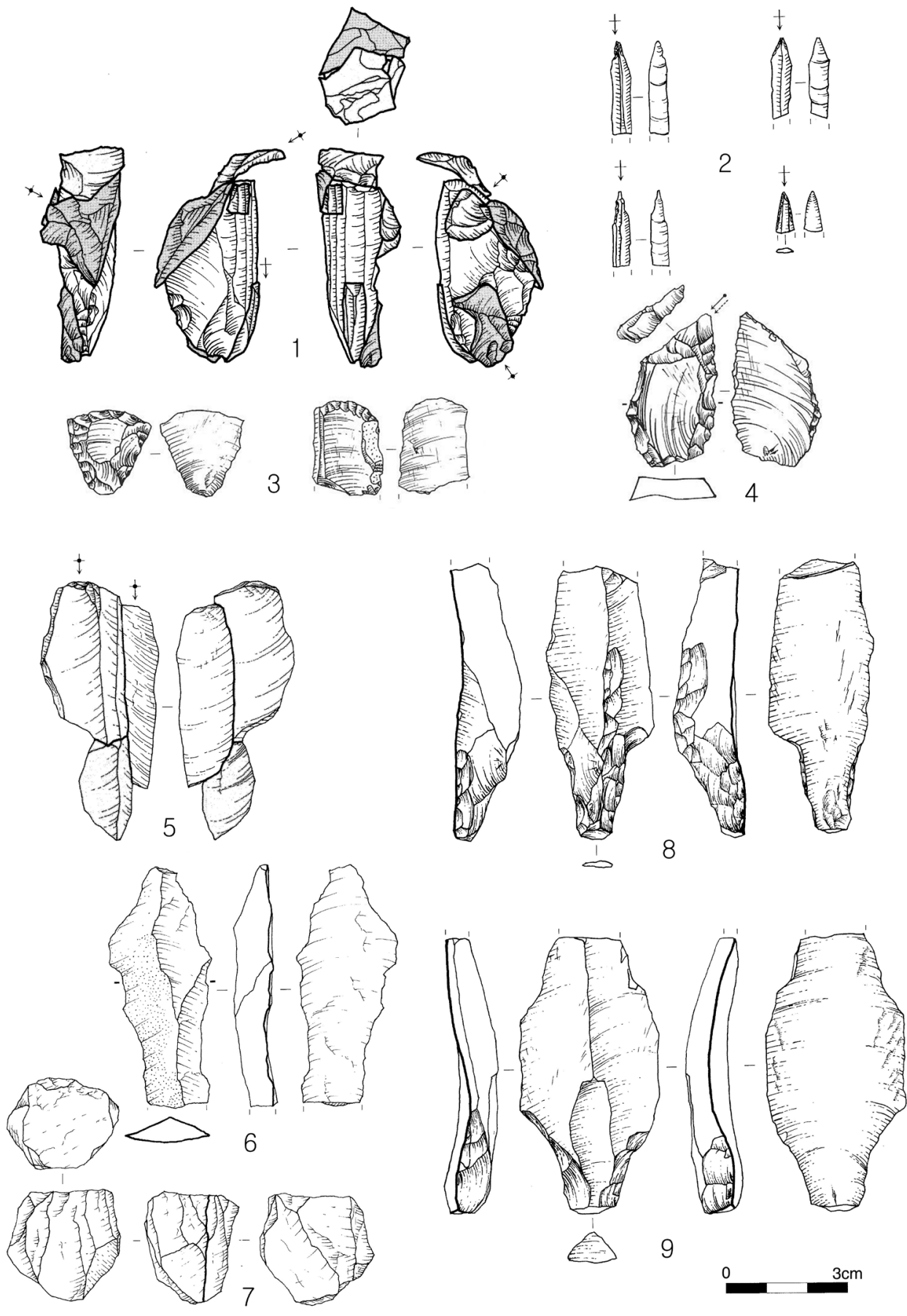

Fig. 2. Late Palaeolithic artifacts from Hopyeong-dong showing the change from the assemblage dominated by tanged points and blades to that led by microliths. Artifacts from the lower horizon include refitted blades (5), vein quartz blades (6), small quartz core (7), and tanged points with broken tips (8 and 9), while the typical microlithic assemblage from the upper horizon include a refitted microblade core (1), microdrills (2), endscrapers (3), and burin (4), all made of obsidian. Source: Adapted from figures in the original excavation report, Hong and Kim 2008. 
Typical blade assemblages are characterized by blades, blade cores, and tanged points, as exemplified by assemblages from Yongsan-dong, Gorye-ri, and the lower horizon at Hopyeong-dong. The AMS dates from these locations range from 27,000 to 23,000 B.P. or $30,000-26,000 \mathrm{cal}$ B.P.

The current archaeological data and radiometric data suggest that a microlithic tradition emerged as early as 30,000 years ago in Korea; this estimate is based on AMS dates from Jangheung-ri $(24,400 \pm 600$ B.P. and 24,200 \pm 600 B.P., or $28521 \pm 1156$ cal B.P. and 28,701 \pm 1224 cal B.P., respectively) and Sinbuk $(23,850 \pm 160$ B.P. and $25,420 \pm 190$ в.P., or 27,969 \pm 332 cal в.P. and 29,580 \pm 577 cal в.P., respectively).

Evaluated radiocarbon dates summarized in Tables 1 and 2 provide valuable information about the duration of typical artifact types. Tanged points first emerged before 35,000 years ago and persisted along with blade and microblade tradition. So far, no tanged points have been recognized in an assemblage dated later than 17,000 B.P., by which time microliths dominated lithic assemblages.

\section{EMERGENCE OF THE LATE PALAEOLITHIC TRADITION}

\section{The Late Palaeolithic Transition}

The transition to the Late or Upper Palaeolithic is usually associated with behavioral modernity (Henshilwood and Marean 2003; McBrearty and Brooks 2000; Mellars 2007), but evidence for such a transition is lacking in the East Asian context (Bae and Bae 2012; Norton and Jin 2009; Qu et al. 2013; Seong 2009a). Allegations that some artifacts are forms of Palaeolithic art or exemplify the capacity for symbolism are dubious at best (C. Bae 2013). For example, we do not have sufficient data from Korea to suggest there was a symbolic explosion of bone and antler tools similar to those associated with the Late (or Upper) Palaeolithic in Africa and Europe.

The transition to the Late Palaeolithic is usually recognized by the establishment of blade technology, with the implication that a transition toward more complex lithic technology inherently connotes the emergence of complex behavioral characteristics; that is, new behaviors and new technology would have been established simultaneously as a "package" (Bar-Yosef 2002, 2007; Bar-Yosef and Kuhn 1999; Brantingham et al. 2004; d'Errico 2003; Kuhn and Stiner 2001; McBrearty 2007). This perspective is compatible with the notion of technological organization; the variability of lithic technology is best understood by the interplay of settlement and mobility systems, raw material quality and availability, and technological and time constraints (Andrefsky 1994, 1998; Bamforth 1986; Binford 1979, 1980, 1983; Chatter 1987; Kuhn 1994; Nelson 1991; Parry and Kelly 1987). A generalized lithic technology (Teltser 1991) is characterized by the flexible strategy of expedient manufacture and use of stone artifacts lacking standardization of tool forms, while a formalized technology is marked by technological and morphological standardization in lithic assemblages.

A formalized lithic technology is often associated with high mobility strategies because standardized artifacts such as blades and blade blanks allow mobile huntergatherers to minimize the weight of carrying stone tools (Kuhn 1994). The transition from a generalized strategy to a formalized lithic technology is not a straightforward, unilineal process, however, since the former is advantageous in situations of low mobility and abundant lithic raw material (Kelly and Todd 1988; Parry and Kelly 1987). The coexistence of diverse lithic assemblages, small quartzite and vein quartz 
assemblages, and blade assemblages described above may represent alternate strategies: one for generalized manufacture using locally available raw material and the other a formalized technology with standardized artifacts made of fine-grained rocks such as siliceous shale and hornfels.

In short, the technological transition to the Late Palaeolithic in Korea is not marked merely by the emergence of blades in a lithic assemblage. Analyses focusing too much on the origin of specific characteristics such as a blade technique may not suitably explain the evolution of lithic technology, especially since blades and even microblades first emerged well before the Upper Palaeolithic (Bar-Yosef and Kuhn 1999; Gamble 2007; Kuhn 2002). Scholars are continuing to address issues regarding the origin of blade and microblade industries in Korea (Bae and Bae 2012; Kuzmin 2007). As more data become accessible, it is likely their origin will be pushed further back in time. This is why we need to look more closely at entire lithic assemblages and note changes in technological organization, assemblage composition, and raw materials, rather than focusing too narrowly on where and when certain technological aspects began and diffused.

Changes in raw material usage are very important in the Korean context. While Early Palaeolithic assemblages are characterized by large and medium-sized artifacts including choppers, polyhedrals, hand axes, flakes, and scrapers, usually made of locally available quartzite, Late Palaeolithic artifacts such as tanged points, blades, endscrapers, burins, and microliths are typically made of fine-grained rocks such as siliceous shale, hornfels, and obsidian that may have been obtained from distant sources. The transition in lithic technology is closely associated with raw material quality and availability. Given the uneven distribution of quality lithic raw material, this has implications for changing mobility strategies.

\section{Tanged Point Assemblages}

The Late or Upper Palaeolithic in Europe and Africa is traditionally defined by the emergence and establishment of blade technology. However, the Early Late Palaeolithic assemblages in Korea, as exemplified at Songam-ri, Yongho-dong, and Hwadae-ri, lack typical blades but are characterized by the presence of tanged points. More than 300 tanged points were recovered from some 30 sites throughout the southern Korean Peninsula (Choi 2014), including Songam-ri, Yongho-dong, Hwadae-ri, Hopyeongdong, Jungmal, Suyanggae, Yongsan-dong, Nosan-ri, Seokjang-ri, Chimgok-ri, Jingeuneul, Bonggok, Haga, Juksan, Wolseong-dong, Wolpyeong, and Sinbuk (Fig. 1). Tanged points are mostly made of siliceous shale or hornfels, the dominant lithic raw materials during the Late Palaeolithic in Korea; they are rarely made of obsidian or quartzite.

At Yongho-dong, two tanged points were uncovered and the layer was AMS dated to $38,500 \pm 1000$ B.P. (Han 2002); more evidence is needed to verify this date. A recent excavation at Songam-ri yielded one tanged point made of quartzite and three made of siliceous shale. The assemblage was dated to $33,300 \pm 160$ B.P. and $33,190 \pm 160$ в.P. or $37,576 \pm 695$ cal B.P. and $37,428 \pm 707$ cal B.P., respectively. Hawdae-ri tanged points are bigger than other varieties from the early phase and are made of coarser grained tuff. A dispersed deposit of charcoal collected near stone artifacts was dated to $31,200 \pm 900$ B.P. or 35,741 $\pm 2000 \mathrm{cal}$ B.P., further supported by the OSL date. 
Whether or not we accept the isolated Yongho-dong date, AMS dates from Songam-ri and Hwadae-ri strongly suggest that lithic assemblages containing tanged points emerged before 35,000 years ago. More importantly, artifacts from these locations do not show indications of use of a blade technique: tanged points were made on flakes, not blades. In other words, at least based on archaeological data currently available, the earliest Late Palaeolithic assemblages characterized by tanged points are not associated with the typical blade technique.

Most tanged points younger than 30,000 B.P. are made from siliceous shale blades, however. Tanged point assemblages from Hopyeong-dong (lower horizon), Daehoesan-ri (Pocheon), Yongsan-dong, and Gorye-ri also contain blades, sometimes large blades, and blade cores, suggesting tanged points and blade technology coexisted. In any case, the Late Palaeolithic tradition in Korea seems to predate the early blade industry of Shuidonggou (Bae et al. 2013).

At Yongsan-dong, more than 20 tanged points (some broken at the base or tip) made of siliceous shale were recovered along with blades and blade cores (JRICH 2007). AMS dating of a soil sample dated the assemblage to $24,430 \pm 870$ B.P. $(28,983 \pm 1706 \mathrm{cal}$ B.P.). Refitted artifacts from Gorye-ri suggest that a tanged point was made of a blade detached from a large blade core that was recovered along with many crested blades and blade cores (Jang 2001; Seo et al. 1999).

As discussed above, one important characteristic of Late Palaeolithic assemblages in Korea may be the long duration of tanged points; they seem to have emerged before 35,000 years ago and lasted until the end of the Last Glacial Maximum (LGM). A significant number of tanged points dated to the LGM have also been uncovered, along with microliths, microblades, and microcores, from Suyanggae, Jangheung-ri, Hopyeong-dong (Sections D and A), and Sinbuk. The significant overlap in duration of different tool types may suggest functional diversification of different point types during the last glacial period (Seong 2008).

\section{THE MICROLITHIC TRADITION}

Evaluated radiocarbon dates suggest that another notable feature of the Late Palaeolithic in Korea is the early appearance of a microlithic tradition (Seong 2011). Early dates from the Altai suggest that techniques for manufacturing microblades existed in Northeast Asia around 35,000 B.P. (Kuzmin 2007). We do not know how soon the tradition dispersed or whether it lasted throughout the last glacial period (Keates 2007). However, drawing on data from regions outside East Asia, scholars have noted that the points of origin of specific cultural traits are not easily identified in the archaeological record, since blade and microblade techniques seem to appear, disappear, and reappear over time in many areas of the world (Gamble 2007; Kuhn 2002). Nonetheless, recent excavations in the southern Korean Peninsula show that the microlithic tradition began before the LGM.

Early microlithic assemblages also contain tanged points and normal-sized blades; these significant components of Late Palaeolithic technology are exemplified in the collections from Jangheung-ri and Sinbuk, which are dated from 30,000 to 27,000 cal B.P. (Lee and Kim 2008) (Table 2). Many assemblages dated to the period widely known as the LGM contain tanged points and microliths made of fine-grained raw materials such as siliceous shale and obsidian. So far, no tanged points have been 
recognized after the LGM (17,000 B.P.), but the microlithic tradition seems to have persisted until the end of the Pleistocene.

Less AMS-dated data are available for the end of the Pleistocene in Korea. While many Late Palaeolithic sites yielded AMS dates falling into the time range of the LGM, we do not yet have reliable dates between 16,000 B.P. and 14,000 B.P. for archaeological sites. Original AMS dates from Hopyeong-dong, where blades and microblades were recovered along with more than 5000 stone artifacts, range from $16,190 \pm 50$ B.P. to $17,400 \pm 400$ B.P. for the upper horizon. Only a few radiometric dates are available after that time.

Microblades and microblade cores from Hahwagye-ri in Hongcheon are mostly made of obsidian; the assemblage is dated to $13,390 \pm 60$ в.P. The Gigok assemblage, marked by blades, microblades, and microcores, includes more than 5000 artifacts made of siliceous shale, obsidian, and quartz crystal. Dated to 10,200 \pm 60 B.P., it may represent the final Pleistocene archaeological occupation in the modern-day Korean Peninsula. Three bifacially worked arrowheads made of quartz crystal were unearthed from Gigok, while one stemmed arrowhead was collected at the nearby Wolso Palaeolithic site. These may indicate the introduction of bow and arrow technology to a local microlithic tradition during the final Pleistocene.

Setting aside the issue of determining the origin and diffusion of the microlithic tradition, which requires more data and a reliable chronology for Korea and adjacent Northeast Asian regions, it seems likely that the wide dispersal of the lithic tradition was driven by increasing population and increasing mobility. As shown in Table 1, many Late Palaeolithic lithic assemblages dated to the LGM are characterized by microlithic artifacts along with tanged points, blades, burins, and endscrapers. The AMS dates seem to suggest that we have more pre-LGM and LGM sites in Korea than post-LGM ones. While it is still not clear whether this implies a lower population density during the post-LGM period, it is significant that the microlithic tradition developed along with preexisting tanged point and blade industries.

Microlithic assemblages in Korea also contain artifacts such as scrapers, endscrapers, burins, awls, and backed knives. Many microdrills made by delicate retouch on microblades were unearthed at Hopyeong-dong. Even groundstone artifacts are not unusual in Late Palaeolithic assemblages; they have been recognized at Yongho-dong, Sinbuk, and Jiphyeon, and recently excavated at Misa-ri.

\section{ISSUES REGARDING THE LATE PALAEOLITHIC IN KOREA}

\section{Raw Material Use}

Raw material quality and availability are important factors constraining the variability of lithic technological organization (Andrefsky 1994, 1998; Bamforth 1986). We need substantial data about raw material sources before we can draw conclusions about related social networks. Quartzite and vein quartz are the most common rocks used for making various large and small tools in the Early Palaeolithic. There are some indications that high-quality local quartzite and vein quartz were also selected to make more formal and smaller tools toward the Late Palaeolithic (Seong 2004). However, finer grained rocks such as silicified tuff (shale), chert, hornfels, and obsidian became more important to the lithic technology of the Late Palaeolithic. Typical Late Palaeolithic artifacts such as tanged points, blades, burins, microblades, and endscrapers were 
dominantly, and in many assemblages exclusively, made of these fine-grained rocks. The distribution and availability of high-quality raw material is far from evident, but it has been suggested that silicified tuff and shale, along with obsidian, are not common in the middle of the Korean Peninsula (Seong 2003, 2004).

Obsidian artifacts have been collected at various locations, mostly from the mid-Korean Peninsula, including Mandal-ri, Jangheung-ri, Jung-ri, Minrak-dong, Sangmuryong-ri, Hahwagye-ri, Gigok, Hopyeong-dong, Misa-ri, Sam-ri, Suyanggae, and Seokjang-ri; they have also been found at some southern sites such as Wolseongdong, Mugeo-dong, Jiphyeon, and Sinbuk (Jang 2013). Current data suggest that obsidian as lithic raw material made an appearance around 25,000 cal B.P., as exemplified by the Hopyeong-dong collection (Hong and Kononenko 2005). Emerging data will soon push obsidian use to an earlier time period. Given the political tensions that prohibit archaeological research in and near the DMZ, we still do not know whether obsidian sources were available in the Korean Peninsula. The closest widely known source is Mt. Baekdu, some $400 \mathrm{~km}$ away from many middle Peninsula sites. While preliminary analyses are far from decisive (Yi and Lee 1996; You et al. 2010), it has been suggested that at least some of these artifacts are made of obsidian originally sourced from Mt. Baekdu or possibly even Kyushu (Lee 2013).

\section{Site Formation Processes and Occupational Diversity}

Different human behaviors leave different material indicators. Palaeolithic assemblages are clearly the remains of mobile hunter-gatherers (Binford 1979, 1980, 1983). We need to understand patterns of artifact distribution by reconstructing natural and behavioral formation processes of archaeological sites (Schiffer 1972, 1987). Studies of natural processes include the determination of fluvial, aeolian, and colluvial deposits. Korean archaeologists have recently been making slow, but significant, improvements in this essential aspect of analysis (Jeong et al. 2013). That features such as fire pits are rarely found in the predominantly open-air Palaeolithic sites suggests that the natural processes of site formation were complex.

As for behavioral processes, researchers on the Korean Palaeolithic conventionally regard refitted artifacts as indications of a lithic tool workshop. Excavators of the Yongsan-dong site, for example, argued that a refitted sample indicated tool manufacture at a workshop (Kim 2004, 2006). The presence of many tanged points broken at the tips and bases is more compatible with a hunting-camp hypothesis, however (Seong 2008). More diverse site types can also be supposed, including hunting camps, limited activity stations, caches, and so forth (Binford 1982; Park 2011).

Lithic workshops are commonly recognized, however. They are especially notable at Suyanggae, where more than 50 clusters of flake and debris scatters with many refitted artifacts have been recovered (Lee 1985). Similar artifacts have recently been excavated at Hajin-ri and Yullyang-dong. In archaeological studies of refitted pieces from these workshops, researchers have focused on identifying various techniques used to manufacture microblades (Jang 2002; Norton et al. 2007; Seong 1998, 2007).

\section{Final Pleistocene and Postglacial Adaptations}

Another potentially important issue is changing population density during the Late Palaeolithic given the substantial geographical and environmental changes that have 
occurred on the Korean Peninsula up until modern times. If we accept the assumption that the number of sites along the chronological axis suggested by available radiocarbon dates provides a proximate measure for occupational history and intensity (Goebel 2002, 2004; Kuzmin 2007, 2008), we may propose a significant change in population density during and after the Late Palaeolithic. Currently available AMS dates indicate that population increased steadily and substantially toward the LGM and then dropped significantly after the LGM (Seong 2011). This is mainly because we have only a small number of archaeological sites dated after the Hopyeong-dong upper horizon (16,000 B.P., or some 19,000 cal B.P.). After that, only a few reliable dates are available, including those from Hahwagye-ri (13,390 \pm 60 B.P.), Songdu-ri $(11,850 \pm 190$ B.P.), and Gigok (10,200 \pm 60 B.P.). Evidence is even scarcer for the time period after the dates for these sites.

One of the most difficult problems in Korean prehistory is explaining the lack of evidence for post-Pleistocene adaptations prior to Neolithic developments. There are few archaeological indications of human occupations during this period. Microliths and arrowheads were recovered from Gosan-ri, along with applique pottery remains resembling those from the lower Amur River basin, but this site is on the southern island of Jeju.

Although we have yet to discover evidence of post-Pleistocene human occupation on the modern-day Korean Peninsula, we cannot conclude that there was no human occupation during that time. Rather, given the substantial archaeological excavations that have been conducted over the last two decades, it is time for researchers to explain the paucity of data and address this issue directly. A rapid rise in sea level and emergence of the peninsular environment could be one explanation for the lack of visible sites. Post-Pleistocene hunter-gatherers might have preferred coastal areas, but their remains would have been submerged in the Yellow Sea. Another explanation has been proposed that emphasizes a rapid restructuring of the environment and changing social networks (Seong 2009b; Whallon 2006). A population packing into favorable regions might have had a domino effect on highly mobile hunter-gatherers and significantly reduced the population in what is now the Korean Peninsula; after that, the peninsula might only have been visited seasonally.

\section{CONCLUSIONS}

Late Palaeolithic assemblages in Korea are characterized by diverse features. While typical Late Palaeolithic industries are characterized by blades and microblades made of fine-grained raw materials, quartzite and vein quartz were still widely used as lithic raw materials to make small flake artifacts in Korea. Some Late Palaeolithic assemblages are exclusively composed of artifacts made of these materials, but there are some indications that high-quality varieties were selected from among locally available lithic material.

Given that transformations in lithic technological organization are associated with changes in raw material use and mobility strategy, the Late Palaeolithic transition in Korea is marked by the manufacture of tanged points and blade assemblages. Currently available archaeological data suggest that tanged points emerged some 40,000 to 35,000 years ago, predating the establishment of a blade industry. The microlithic tradition appeared some 25,000 B.P. (30,000 cal B.P.), but coexisted with tanged points and blades for a substantial time during the Last Glacial Maximum. The microlithic 
tradition persisted until the very end of the Pleistocene, but we do not have substantial evidence for a post-Pleistocene adaptation in the Korean Peninsula.

\section{ACKNOWLEDGMENTS}

I benefited from the constructive comments of Dr. Laura Lee Junker, Professor Christopher Bae, and Professor Jangsuk Kim. This work was supported by the National Research Foundation of Korea Grant funded by the Korean Government (NRF2013S1A5B6043901).

\section{REFERENCES CITED}

ANDREFSKy, William, JR.

1994 Raw material availability and the organization of technology. American Antiquity 59(1):21-35.

1998 Lithics: Macroscopic Approaches to Analysis. Cambridge: Cambridge University Press.

Bae, Christopher J.

2013 Palaeolithic cave home bases, bone tools, and art and symbolism: Perspectives from Korea. Hoseo Gogohak 29:50-77.

Bae, Christopher J., and Kidong Bae

2012 The nature of the Early to Late Palaeolithic transition in Korea: Current perspectives. Quaternary International $281: 25-35$.

Bae, Christopher J., Kidong Bae, and Jong Chan Kim

2013 The Early to Late Palaeolithic transition in Korea: A closer look. Radiocarbon 55(2-3): 13411349.

BAE, KIDONG

2013 Palaeolithic culture in Korea, in Dictionary of Korean Archaeology: The Palaeolithic Age: 388-390. Seoul: National Research Institute of Cultural Heritage.

BAmForth, Douglas B.

1986 Technological efficiency and stone tool curation. American Antiquity 51:38-50.

BAR-YOSEF, OFER

2002 The Upper Palaeolithic revolution. Annual Review of Anthropology 31:363-393.

2007 The dispersal of modern humans in Eurasia: A cultural interpretation, in Rethinking the Human Revolution: New Behavioural and Biological Perspectives on the Origin and Dispersal of Modern Humans: 207-217, ed. P. Mellars, Katie Boyle, O. Bar-Yosef, and C. Stringer. Cambridge: McDonald Institute for Archaeological Research.

Bar-Yosef, Ofer, and Steven L. Kuhn

1999 The big deal about blades: Laminar technologies and human evolution. American Anthropologist 101(2):322-338.

BINFORD, LEWIS R.

1979 Organization and formation processes: Looking at curated technologies. Journal of Anthropological Research $35: 255-273$.

1980 Willow smoke and dog's tails: Hunter-gatherer settlement systems and archaeological site formation. American Antiquity 45:4-20.

1982 The archaeology of place. Journal of Anthropological Archaeology 1:5-31.

1983 In Pursuit of the Past. London: Thames and Hudson.

Brantingham, P. Jeffrey, Steven L. Kuhn, and Kristopher W. Kerry

2004 The Early Upper Palaeolithic and modern human behavior, in The Early Upper Palaeolithic Beyond Western Europe: 242-248, ed. P. J. Brantingham, S. L. Kuhn, and K. W. Kerry. Berkeley: University of California Press.

Chatter, James C.

1987 Hunter-gatherer adaptations and assemblage structure. Journal of Anthropological Research $6: 336-375$.

Choi, B. K., S. M. An, And H. J. Ryu

2004 The Hahwagye-ri Palaeolithic Site, Hongcheon. Chuncheon: Institute of Gangwon Archaeology (in Korean). 
Choi, B. K., S. M. An, H. J. Ryu, And J. H. Moon

2003 The Nobong Palaeolithic Site. Chuncheon: Institute of Gangwon Archaeology (in Korean).

Choi, B. K., S. Y. Choi, S. Y. Сhoi, H. Y. Lee, and J. J. Cha

2001 The Jangheung-ri Palaeolithic Site. Chuncheon: Institute of Gangwon Archaeology (in Korean).

Choi, Cheol-min

2014 A Study of Late Palaeolithic Tanged Points from Korea. Master's thesis. Department of History, Kyung Hee University, Seoul (in Korean).

Derev'anko, A. P., AND S. Markin

1998 The Palaeolithic of the Altai, in Palaeolithic of Siberia: New Discoveries and Interpretations: 84-106, ed. A. P. Derev'anko, D. B. Shimkin, and W. R. Powers. Urbana: University of Illinois Press.

Derevianko, A. P., P. J. Brantingham, J. W. Olsen, and D. Tseveendorj

2004 Initial Upper Palaeolithic blade industries from the north-central Gobi Desert, Mongolia, in The Early Upper Palaeolithic beyond Western Europe: 207-222, ed. P. J. Brantingham, S. L. Kuhn and K. W. Kerry. Berkeley: University of California Press.

d’Errico, F., C. Henshilwood, G. Lawson, M. Vanhaeren, A.-M. Tillier, M. Soressi, F. Bresson, B. Maureille, A. Nowell, J. Lakarra, L. Backwell, and M. Julien

2003 Archaeological evidence for the emergence of language, symbolism, and music: An alternative multidisciplinary perspective. Journal of World Prehistory 17(1): 1-70.

Gamble, Clive

2007 Origins and Revolutions: Human Identity in Earliest Prehistory. Cambridge: Cambridge University Press.

Gao, Xing, and Christopher Norton

2002 A critique of the Chinese "Middle Palaeolithic." Antiquity 76:397-412.

GOEBEL, TED

2002 The "microlithic adaptation" and recolonization of Siberia during the late Upper Pleistocene, in Thinking Small: Global Perspectives on Microlithization: 117-132, ed. R. G. Elston and S. L. Kuhn. Washington, D.C.: Archaeological Papers of the American Anthropological Association.

2004 The Early Upper Palaeolithic of Siberia, in The Early Upper Palaeolithic beyond Western Europe: 162-195, ed. P. J. Brantingham, S. L. Kuhn, and K. W. Kerry. Berkeley: University of California Press.

Graf, Kelly E.

2009 "The good, the bad, and the ugly": Evaluating the radiocarbon chronology of the Middle and Late Upper Palaeolithic in the Enisei River valley, south-central Siberia. Journal of Archaeological Science 36:694-707.

Han, Chang-Gyun

2002 The Yongho-dong site and Palaeolithic culture. Daejeon Munhwa 11:91-105 (in Korean).

Henshilwood, C. S., and C. W. Marean

2003 The origin of modern human behavior: Critique of the models and their test implications. Current Anthropology 44(5) : 627-651.

Hong, Mi-Young, And JongheOn Kim

2008 The Hopyeong-dong Palaeolithic Site, Namyangju. Suwon: Gijeon Institute of Cultural Properties (in Korean).

Hong, Mi-Young, And Nina Kononenko

2005 Obsidian artifacts and their function from the Hopyeong-dong Palaeolithic site, Namyangju. Hanguk Guseokki Hakbo 12:1-30.

IкAwa-Smith, Fumiko

1978 Introduction: The Early Palaeolithic tradition of East Asia, in Early Palaeolithic in South and East Asia: 1-10, ed. F. Ikawa-Smith. Chicago: Mouton Publishers.

JANG, YONG-Jun

2001 Core reduction processes during the Late Palaeolithic. Hanguk Guseokki Hakbo 4:43-64 (in Korean).

2002 Chronological study of microblade cores in Korea. Hanguk Gogo Hakbo 48: 5-33 (in Korean).

2013 On the study of obsidian artifacts from Korea. Paper presented at the 2013 Annual Meeting of Korean Palaeolithic Society, Wonju, Korea (in Korean). 
Jeong, Gi-Young, Jung-Heon Choi, Hyun-Soo Lim, Chuntaex Seong, and Seonbok Yi

2013 Deposition and weathering of Asian dust in Palaeolithic sites, Korea. Quaternary Science Reviews 78:283-300.

Jeong, Y. W., D. S. Go, S. Y. Park, S. H. Hong, J. J. Lee, S. Y. Kim, and S. M. Park

2011 The Anhyeon-dong Site, Gangneung. Chuncheon: Yemaek Research Institute for Cultural Heritage (in Korean).

Ji, H. B., H. Y. Lee, C. H. Lee, Y. S. Choi, and N. R. Lee

2007 The Pyeongneung-dong Palaeolithic Site, Donghae. Chuncheon: Gangwon Research Institute for Cultural Heritage (in Korean).

JRiCH (Jungang Research Institute of Cultural Heritage)

2007 The Yongsan-dong Palaeolithic Site. Daejeon: JRICH (in Korean).

Keates, Susan

2007 Microblade technology in Siberia and neighboring regions: An overview, in Origin and Spread of Microblade Technology in Northern Asia and North America: 125-146, ed. Y. V. Kuzmin, S. G. Keates, and Chen Shen. Burnaby, BC: Archaeology Press, Simon Fraser University.

Kelly, Robert L., And L. C. Todd

1988 Coming into the country: Early Paleoindian hunting and mobility. American Antiquity $53: 231-244$.

Kim, Hwan-IL

2004 The Yongsan-dong Palaeolithic site, Daejeon. Hanguk Guseoki Hakbo 10:83-94 (in Korean).

2006 The characters of tanged points from Yongsan-dong Palaeolithic site, Daejeon, Korea. Research Proceedings of Institute of Jungang Cultural Properties 2:1-21 (in Korean).

Kim, J. Y., Y. C. Park, D. Y. Yang, P. Y. Bong, Y. N. Seo, Y. S. Lee, and J. G. Kim

2002 Reconstruction of depositional environment at Jangheung-ri, Jiphyeon. Hanguk Sagihakheoji 16(2):9-23.

Kim, So-Young

2010 The Hopyeong-dong Palaeolithic Site III, Namyangju. Suwon: Gyeonggi Research Insititute for Cultural Heritage (in Korean)

Kim, Y. H., D. J. LeE, Y. D. Kim, S. W. Jang, AND J. M. Kim

2010 The Wadong-ri IV Site, Paju. Suwon: Gyeonggi Research Institute for Cultural Heritage (in Korean).

Kuhn, Steven L.

1994 A formal approach to the design and assembly of mobile toolkits. American Antiquity $59: 426-442$

2002 Pioneers of microlithization: The "Proto-Aurignacian" of southern Europe, in Thinking Small: Global Perspectives on Microlithization: 83-94, ed. E. G. Elston and S. L. Kuhn. Archaeological Papers of the American Anthropological Association, Number 12. Washington, D.C.: AP3A.

Kuhn, Steven L., and Mary C. Stiner

2001 The antiquity of hunter-gatherers, in Hunter-Gatherers: An Interdisciplinary Perspective: 99-142, ed. C. Paner-Brick, R. H. Layton, and P. Roley-Conwy. Cambridge: Cambridge University Press.

Kuzmin, Yaroslav V.

2007 Geoarchaeological aspects of the origin and spread of microblade technology in northern and central Asia, in Origin and Spread of Microblade Technology in Northern Asia and North America: 1115-1124, ed. Y. V. Kuzmin, S. G. Keates, and Chen Shen. Burnaby, BC: Archaeology Press, Simon Fraser University.

2008 Siberia at the Last Glacial Maximum: Environment and archaeology. Journal of Archaeological Research 16:163-221.

LEE, GI-KIL

2013 On the obsidian artifacts from Sinbuk, Jangheung. Paper presented at the 2013 Annual Meeting of the Korean Palaeolithic Society, Wonju, Korea (in Korean).

Lee, Gi-Kil, M. A. Cha, AND S. A. Kim

2008 The Imsil Haga Site. Gwangju: Chosun University Museum (in Korean).

LeE, Gi-Kil, AND Myung-Jin Kim

2008 Absolute chronology of Sinbuk Upper Palaeolithic Site in southwestern Korea by calibrating radiocarbon dates with CalPal 2007 Hulu curve. Honam Gogo Hakbo 29:5-24. 
LeE, HeOn-Jong

2004 Correlation of chronology and techno-typological character of Upper Palaeolithic in Korea. Hanguk Sanggosa Hakbo 44:5-22 (in Korean).

Lee, H. J., J. T. Choi, and S. H. Park

2002 The Excavation Report of the Daejeong-dong Site. Jochiwon: Korea University Research Institute for Cultural Heritage (in Korean).

Lee, H. Y., Y. S. Choi, ANd N. R. LeE

2009 The Mangsang-dong Palaeolithic Site, Daonghae. Chuncheon: Gangwon Research Institute for Cultural Heritage (in Korean).

Lee, H. Y., S. H. Hong, AND Y. S. Choi

2005 The Gigok Palaeolithic Site, Donghae. Chuncheon: Gangwon Research Institute for Cultural Heritage (in Korean).

LEE, YUNG-JO

1985 An excavation report on the Palaeolithic site of Suyanggae, Danyang, in Chungju Dam Submerging Area Archaeological Reports: 101-251, ed. Chungbuk National University Museum. Cheongju: Chungbuk National University Museum (in Korean).

Lee Y. J., T. Cho, S. Kong, and S. Lee

2006 The Songdu-ri Palaeolithic Site: An Excavation Report. Cheongju: Jungwon Institute of Cultural Properties (in Korean).

Lee, Y. J., S. Kong, H. Lee, J. Kim, D. Yang, and J. Kim

2002 Test excavation report at the Nosan-ri site, Cheongwon. Cheongju: Chungbuk National University Museum (in Korean).

Lim, Y. H., B. H. You, M. Y. Sin, AND H. J. Kim

2007 The Changdeok Site, Yongin. Foundation for Conservation of Korean Cultural Heritage (in Korean).

McBrearty, SAlly

2007 Down with the revolution, in Rethinking Human Revolution: New Behavioural and Biological Perspectives on the Origin and Dispersal of Modern Humans: 133-151, ed. P. Mellars, Katie Boyle, O. Bar-Yosef, and C. Stringer. Cambridge: McDonald Institute for Archaeological Research.

McBrearty, Sally, and Alison. S. Brooks

2000 The revolution that wasn't: A new interpretation of the origin of modern human behavior. Journal of Human Evolution 39: 453-563.

Mellars, Paul

2007 Rethinking the Human Revolution: Eurasian and African perspectives, in Rethinking the Human Revolution: New Behavioural and Biological Perspectives on the Origin and Dispersal of Modern Humans: 1-11, ed. P. Mellars, Katie Boyle, O. Bar-Yosef, and C. Stringer. Cambridge: McDonald Institute for Archaeological Research.

Nelson, Margaret C.

1991 The study of technological organization, in Archaeological Method and Theory 3:57-100, ed. M. B. Schiffer. Tucson: University of Arizona Press.

Norton, Christopher J., Kidong Bae, H. Y. Lee, and J.W.K. Harris

2007 A review of Korean microlithic industries, in Origin and Spread of Microblade Technology in Northern Asia and North America: 91-102, ed. Y. V. Kuzmin, S. G. Keates, and Chen Shen. Burnaby, BC: Archaeology Press, Simon Fraser University.

Norton, Christopher J., And Jennie J. H. Jin

2009 The evolution of modern humans in East Asia: Behavioral perspectives. Evolutionary Anthropology 18:247-260.

PARK, SEONG-Jin

2011 A preliminary investigation on discerning the function of sites in Upper Palaeolithic in Hungwon region of Korea. Hanguk Guseokgi Hakbo 24 :21-44.

PARK, Young-Chul

2002 An analysis of Middle Palaeolithic stone artifacts from Korea. Hanguk Guseokki Hakbo 5: 1-58 (in Korean). 
Parry, William J., and Robert L. Kelly

1987 Expedient core technology and sedentism, in The Organization of Core Technology: 285-304, ed. J. K. Johnson and C. A. Morrow. Boulder, CO: Westview Press.

Qu, Tongli, Ofer Bar-Yosef, Youping Wang, and Xiaohong Wu

2013 The Chinese Upper Palaeolithic: Geography, chronology and techno-typology. Journal of Archaeological Research $21: 1-73$.

SCHIFFER, M. B.

1972 Archaeological context and systemic context. American Antiquity 37:156-165.

1987 Formation Processes of the Archaeological Record. Albuquerque: University of New Mexico Press.

SeO, Y. N., H. J. Kim, AND Y. J. JANG

1999 Palaeolithic culture of Gorye-ri, Milyang, in Palaeolithic Culture of Yeongnam. Collected Papers of the 8th Symposium on the Archaeology of the Yeongnam Region, Daegu, Korea, April 1999: 47-63. Daegu: Yeongnam Archaeological Society (in Korean).

SeOng, Chuntaek

1998 Microblade technology in Korea and adjacent Northeast Asia. Asian Perspectives 37:245278.

2002 The relevance of the Middle Palaeolithic in Korea: A critical review. Hanguk Gogo Hakbo 46:5-28 (in Korean).

2003 Late Palaeolithic raw materials in Korea: A preliminary analysis. Hanguk Sanggosa Hakbo 39: 1-18 (in Korean).

2004 Quartzite and vein quartz as lithic raw materials reconsidered: A view from the Korean Palaeolithic. Asian Perspectives 43 : 73-91.

2007 Late Pleistocene microlithic assemblages in Korea, in Origin and Spread of Microblade Technology in Northern Asia and North America: 103-114, ed. Y. V. Kuzmin, S. G. Keates, and Chen Shen. Burnaby, BC: Archaeology Press, Simon Fraser University.

2008 Tanged points, microliths, and Late Palaeolithic hunting in Korea. Antiquity 8:871-883.

$2009 a$ Emergence of a blade industry and evolution of Late Palaeolithic technology in Republic of Korea. Journal of Anthropological Research 65 : 417-451.

$2009 b$ Hunter-gatherer mobility and postglacial cultural change in southern Korean Peninsula. Hanguk Gogo Hakbo 72:4-35 (in Korean).

2011 Evaluating radiocarbon dates and Late Palaeolithic chronology in Korea. Arctic Anthropology 48:93-112.

Teltser, Patrice A.

1991 Generalized core technology and tool use: A Mississippian example. Journal of Field Archaeology $18: 363-375$.

WhALLON, ROBERT

2006 Social networks and information: Non-“utilitarian” mobility among hunter-gatherers. Journal of Anthropological Archaeology 25 : 259-270.

Yang, J.-S., M.-Y. Hong, J.-R. Kim, N.-H. Kim, And J.-H. Kim

2008 The Deokso Site, Namyangiu. Suwon: Suwon University Museum.

Yi, SEONBOK

1989 A Study of the Palaeolithic of Northeast Asia. Seoul: Seoul National University Press (in Korean).

Yi, SeOnbok, AND YongIL LeE

1996 A preliminary analysis of geochemical properties of obsidian artifacts. Hanguk Gogo Hakbo 35: 173-187 (in Korean).

Yi, SeOnbok, T. SODA, AND F. Arai

1998 New discovery of Aira-Tn ash (AT) in Korea. Journal of Korean Geographical Society 33:447454.

Yi, Seonbor, Yongwook Yoo, and Chuntaek Seong

2000 The Pyeongchang-ri Palaeolithic Site. Seoul: Kyonggido (Gyeonggi-do) Museum and Seoul National University (in Korean).

You, Mi-Yeon, Chan-Hee Lee, Myung-Jin Kim, Sang-Hoon Bae, and Chang-Kyun Han

2010 Material analysis and geoarchaeological interpretation of the obsidian artifact collected at Daebak-ri site, Cheongyang, Korea. Hanguk Guseokgi Hakbo 21 :21-38. 


\begin{abstract}
One of the most characteristic aspects of the Late Palaeolithic in Korea is the diversity of lithic assemblages. Assemblages dominated by quartzite and vein quartz artifacts persisted throughout the Palaeolithic, while blade and microblade assemblages mark the typical Late Palaeolithic technology. Still, given that lithic technological organization is characterized by the interplay of technical constraints, raw material availability, and huntergatherer mobility, the transition to the Late Palaeolithic technology is closely associated with the emergence of tanged points, dated to 40,000 to $35,000 \mathrm{cal}$ в.P., made of such fine-grained rocks as silicified tuff and shale, other than locally available quartzite. Tanged points persisted along with blades and blade cores until the end of the LGM, and the microlithic assemblage emerged as early as 30,000 cal B.P. as AMS dates from Jangheungri and Sinbuk suggest. Only a few radiometric dates are available for post-LGM occupations and there may have been a significant decrease in mobile hunter-gatherer populations in the post-glacial Korean Peninsula. Keywords: blades, Korea, Late Palaeolithic, lithics, microlithic, radiocarbon dating, tanged points.
\end{abstract}

